\title{
A glimpse into the molecular entrails of endoderm formation
}

\author{
Didier Y.R. Stainier \\ Department of Biochemistry and Biophysics, Programs in Developmental Biology, Genetics, and Human Genetics, \\ University of California, San Francisco, San Francisco, California 94143-0448, USA
}

\begin{abstract}
During organogenesis, the endoderm forms the epithelial lining of the primitive gut tube from which the alimentary canal and associated organs, such as the liver and pancreas, develop. Despite the physiological importance of these organs, our knowledge of the genes regulating endoderm development has been limited. In the past few years, we have witnessed a rapid pace of discoveries regarding the initial formation of this germ layer. Because the insights have come from studies in several model systems, I have chosen to discuss endoderm formation not only in vertebrate model systems but also in Caenorhabditis elegans, Drosophila, sea urchins, and ascidians. These studies reveal a high degree of conservation in some of the transcriptional regulators of endoderm differentiation, but seemingly more divergence in the intercellular signaling events leading to formation of this tissue. For example, transcription factors of the Gata and Forkhead families are implicated in endoderm development across the phyla. On the other hand, a role for TGF- $\beta$, and more specifically Nodal, signaling, which is critical for endoderm formation in zebrafish, mouse, and Xenopus, appears to be vertebrate specific. The studies on vertebrate endoderm formation also suggest that we have now gathered sufficient information to attempt to coax mammalian stem cells towards the endodermal lineage.
\end{abstract}

\section{Definition of the endoderm}

The endoderm is classically defined as the innermost layer of the three Metazoan "germ layers" and as such it gives rise to the inner lining of the gut and its associated organs. However, the term "endoderm" has also been coopted for other developing structures such as some of the extraembryonic tissues in mammalian embryos. Until the time when the nomenclature is adequately revised, the classically defined embryonic endoderm is often referred to as "definitive endoderm" and these are the cells whose formation, or initial differentiation, I will cover in this review. In addition and to establish

E-MAIL didier_stainier@biochem.ucsf.edu; FAX (415) 476-3892. Article and publication are at http://www.genesdev.org/cgi/doi/10.1101/ gad.974902. some temporal distinction, I refer to cells as progenitors prior to the onset of gastrulation, and precursors during gastrulation stages. Finally, because the endoderm and mesoderm often originate from the same, or adjacent, regions of the embryo, a recurring theme of this review will be the analysis of how the embryo segregates these two germ layers.

\section{Endoderm formation in C. elegans}

The entire endoderm in C. elegans, that is, the 20 cells that constitute the intestine, originates from the $\mathrm{E}$ blastomere at the 8-cell stage (Fig. 1A) (Sulston et al. 1983). E itself is a daughter of EMS and the sister of MS, which gives rise to much of the mesoderm. Endoderm formation in C. elegans is under the control of a number of maternal proteins, including SKN-1, a bZIP/homeodomain transcription factor that is required for both $\mathrm{E}$ and MS development (Bowerman et al. 1992). SKN-1 directly regulates the expression of two redundant GATA-type transcription factor genes, med-1 and med-2, which like skn-1 are necessary for EMS differentiation (Maduro et al. 2001). In addition, ectopic expression of either MED-1 or MED-2 can induce mesendodermal differentiation in non-EMS cells (Maduro et al. 2001).

Downstream of MED-1 and MED-2, lie END-1 and END-3, another pair of redundant GATA factors. Losing both END-1 and END-3 results in the loss of endoderm (Zhu et al. 1997). In fact, the 'endodermal' phenotype of these mutants is very similar to that seen in skn-1 and med-1,2 mutants in that the E blastomere is converted to a C-like mesoectodermal progenitor. (The $\mathrm{C}$ blastomere, which is a daughter of $\mathrm{P} 2$, gives rise primarily to epidermis and muscle.) Shortly after the time $\mathrm{E}$ is born and end-1 and end-3 become activated, two additional GATA factors, ELT-2 and ELT-7 become expressed (Fukushige et al. 1998). Loss of ELT-2 alone leads to degeneration of the gut, whereas loss of ELT-7 alone does not appear to have any phenotype. However, ELT-2 and ELT-7 again appear to function redundantly in gut development as removal of both has a more profound effect on gut differentiation than removal of ELT-2 alone and abrogates transcription of many gut-specific genes. Ectopic expression of any of these endoderm specific GATA factors (END-1, END-3, ELT-2, or ELT-7) is sufficient to 
A. C. elegans

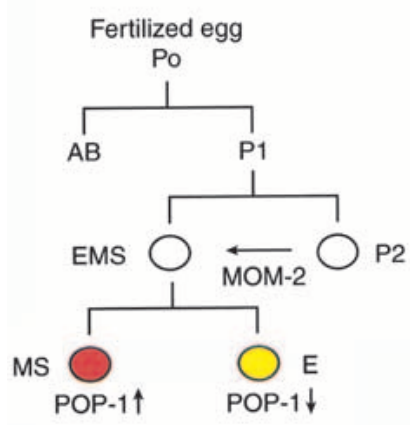

D. Xenopus
B. Drosophila

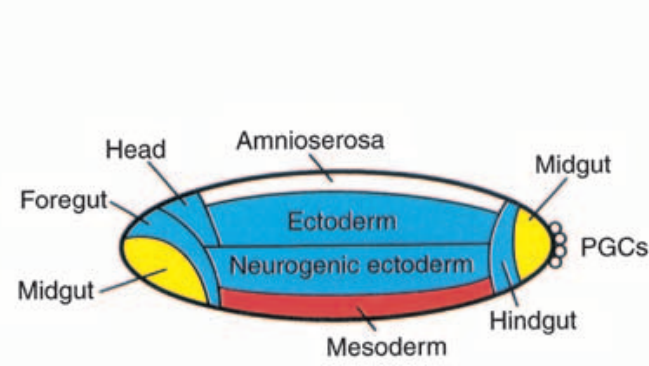

E. zebrafish

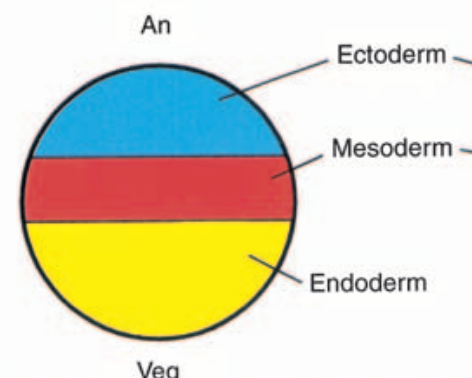

Veg

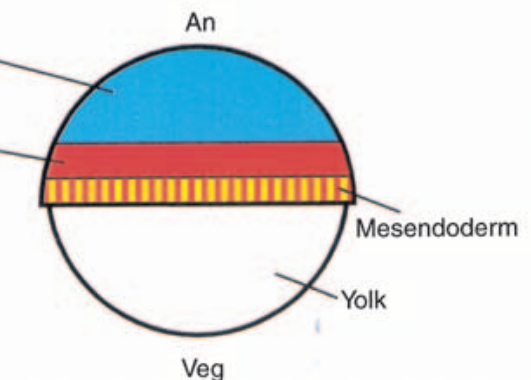

Veg
C. sea urchin

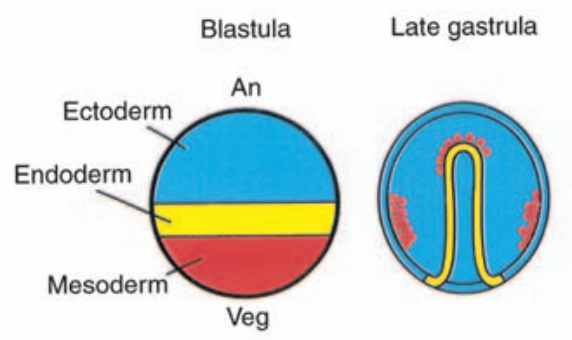

Figure 1. Early cell lineage of the Caenorhabditis elegans embryo and fate maps of the Drosophila, sea urchin, Xenopus, zebrafish and mouse embryos showing the position of the mesodermal (red) and endodermal (yellow) progenitors. (A) In C. elegans, the mesendodermal progenitor EMS divides to give rise to MS, the mesodermal progenitor, and E, the endodermal progenitor. Prior to this division, P2 sends EMS a Wnt signal (encoded by mom-2) which leads to a decrease in POP-1 function in E, allowing endoderm formation. (B) In Drosophila, endodermal tissues originate from the poles of the blastoderm embryo. Note that both the foregut and hindgut are thought to be ectodermal (blue). $(C)$ In sea urchin, the mesoderm lies vegetal to the endoderm so that during gastrulation, the mesoderm invaginates first followed by the endoderm. By the end of gastrulation, the endoderm forms the archenteron or primitive gut. $(D)$ In Xenopus, as in ascidians, most of the endoderm derives from the most vegetal aspect of the late blastula stage embryo. The suprablastoporal endoderm is not shown in this simplified drawing. $(E)$ In zebrafish, the endoderm lies close to the margin at the late blastula stage. Mesodermal and endodermal progenitors are interspersed in this region while further away from the margin only mesodermal progenitors are present. (F) In mouse figure adapted from Wells and Melton (1999), gastrulation begins when mesodermal and endodermal progenitors start migrating through the primitive streak. After passing through the streak, the endodermal precursors and some mesodermal precursors, including those that will give rise to the notochord, migrate along the midline in an anterior direction. Other populations of mesodermal cells migrate more laterally. (PGCs) Primordial germ cells; (An) animal pole; (Veg) vegetal pole; (A) anterior; (P) posterior.

promote widespread gut formation throughout the embryo (Zhu et al. 1998; J. Rothman, pers. comm.). Yet another GATA factor, ELT-4, is expressed later in gut development, though its function is unknown (J. McGhee, pers. comm.). Thus a network of GATA factors that act in redundant pairs functions to regulate endoderm formation and gut development in C. elegans. In fact, of the 11 GATA factors in C. elegans, seven are involved in endoderm development.

In addition to these GATA factors, a large number of other transcription factors are specifically expressed in the endoderm. These include a Forkhead-domain transcription factor, PHA-4, which is expressed throughout the intestine (Azzaria et al. 1996; Horner et al. 1998; Kalb et al. 1998) and at higher levels throughout the pharynx, the anterior organ of the digestive tract. Although PHA-4 is essential for differentiation of the five different cell types of the pharynx (Mango et al. 1994; Horner et al. 1998), its role in gut differentiation is not known. The presence of GATA sites within its promoter suggests that at least part of pha-4 expression is regulated by member(s) of the GATA network (Kalb et al. 1998).

The segregation of mesoderm and endoderm, which happens when EMS divides, is regulated by a Wnt signal that originates from P2, a cell adjacent to EMS (Fig. 1A). Mutations that lead to the transformation of $\mathrm{E}$ to MS (More of MS, MOM), or the transformation of MS to E (Posterior Pharynx Deleted, POP) have been identified and found to encode components of convergent Wnt and MAP kinase signaling cascades (for review, see Thorpe et al. 2000). These signals allow endoderm development to occur. For example, mom-2 encodes the Wnt protein 
necessary for endoderm formation (Thorpe et al. 1997), whereas pop-1 encodes a Tcf homolog that inhibits endoderm formation (Lin et al. 1995). Additional components of this pathway include WRM-1, a $\beta$-catenin homolog necessary for endoderm formation (Rocheleau et al. 1999), and MOM-4, a MAP3K also necessary for endoderm formation (Meneghini et al. 1999; Shin et al. 1999). A model of how this Wnt-MAPK signaling pathway integrates with the MED transcription factors to positively regulate the expression of the endoderm-specifying end genes has been proposed by Maduro et al. (2001). According to this model, which has been partially tested, the MEDs activate the end genes in E, while in MS, POP-1 repression of the end genes (Calvo et al. 2001) allows the MEDs to activate MS-specific target genes. In summary, many of the regulators of early endoderm development have been identified in C. elegans and assembled into a molecular pathway (Fig. 2A). It will be particularly interesting to further explore issues such as the sufficiency of Wnt signaling in endoderm formation, especially in light of data obtained in sea urchins and ascidians (see below).

\section{Endoderm formation in Drosophila}

In Drosophila, the endodermal tissues originate from the most terminal aspects, or poles, of the blastoderm embryo (Fig. 1B). The anterior pole gives rise to the anterior midgut, the posterior pole to the posterior midgut, and the midgut proper is derived from cells that migrate from both anterior and posterior primordia. Several mutations that affect the formation of endodermal tissues have been identified and analyzed in detail, including huckebein, serpent, and fork head. huckebein encodes an $\mathrm{Sp} 1 /$ Egr-like $\mathrm{Zn}$-finger protein and is expressed in the terminal regions of the embryo (Bronner et al. 1994). It interacts with snail and twist to separate the endoderm from the mesoderm prior to gastrulation. In huckebein mutants, the mesodermal progenitors expand at the expense of the endoderm and both midgut primordia are absent. At the molecular level, Huckebein has been proposed to repress the function of Snail and Twist in the endodermal progenitors (Reuter and Leptin 1994). Huckebein also positively regulates the expression of the GATA gene serpent in the midgut primordia and serpent itself is required for midgut development (Reuter 1994). In serpent mutants, the midgut primordia invaginate, but the cells do not appear to undergo the epithelial-tomensenchymal transition that normally precedes migration (Reuter 1994). In other settings, serpent has also been implicated in cell fate decisions (Rehorn et al. 1996; Hayes et al. 2001), indicating that GATA genes function in both morphogenesis and cell differentiation. fork head mutants also lack a gut and fork head encodes the founding member of the winged-helix transcription factors now known as Fox (Forkhead box) factors (Weigel et al. 1989; Kaestner et al. 2000). (Chordate homologs of fork head are also involved in endoderm development and are covered below.) The expression pattern of fork head in Drosophila is associated with the invagination of the gut primordia suggesting that it regulates this process. In fact, analysis of fork head function in the secretory cells of the Drosophila salivary gland shows that it is required for constriction of the apical surface membrane (Myat and Andrew 2000), a process necessary for cell invagination. Another gene expressed in the Drosophila midgut is hepatocyte nuclear factor $4(H N F 4)$, which encodes a member of the steroid hormone receptor superfamily and, as its name indicates, has been associated with endoderm development in vertebrates (Zhong et al. 1993). At this point however, its function or position within the developmental hierarchy leading to endoderm formation in Drosophila are not known. It is interesting to note that in C. elegans, another putative member of this steroid hormone receptor superfamily, END-2, has also been implicated in endoderm formation (Zhu et al. 1997) although its exact role remains unclear.

Another area of active investigation in Drosophila is the anterioposterior patterning of the gut endoderm by the overlying mesoderm. This fascinating question, which falls outside the scope of this review, has been recently synthesized elsewhere (Bienz 1997; Clements et al. 2001). In addition, the hindgut, although thought to arise from the ectoderm in insects, requires for its formation an evolutionarily conserved "cassette" that includes Fork head and a Wnt signal (for review, see Lengyel and Iwaki 2002).

\section{Endoderm formation in sea urchin}

The sea urchin endoderm originates from the vegetal plate of the blastula stage embryo (Fig. 1C). Endoderm morphogenesis begins by an inward bending of the vegetal plate to form a pocket of $\sim 100$ cells. This process, called primary invagination, results in a short, squat stump of tissue (the archenteron or primitive gut), which contains most of the endodermal precursors as well as precursors of the secondary mesenchyme (SMC). (The SMC precursors become mesenchymal during gastrulation and go on to form a diverse array of cell types including muscle and pigment cells.) Subsequently, the archenteron elongates as the cells in this invaginated epithelium rearrange and more endodermal cells are recruited around the blastopore (the opening of the archenteron at the vegetal region) in a process referred to as secondary invagination. Finally, in the animal pole region of the embryo, the archenteron contacts the basal surface of the presumptive ectoderm, which leads to the formation of the mouth opening.

Several genes expressed specifically in endodermal precursors during gastrulation have been identified. One of them, endo16, which encodes an extracellular matrix glycoprotein, has been examined in detail in an attempt to elucidate the regulatory circuits controlling gene expression in the developing endoderm. Specifically, extensive analysis of the endo16 promoter has led to the identification of the binding sites critical for endodermal expression as well as the purification and molecular isolation of many of the binding factors (Yuh et al. 1998, 2001). From these and other studies a detailed picture of 
A. C. elegans

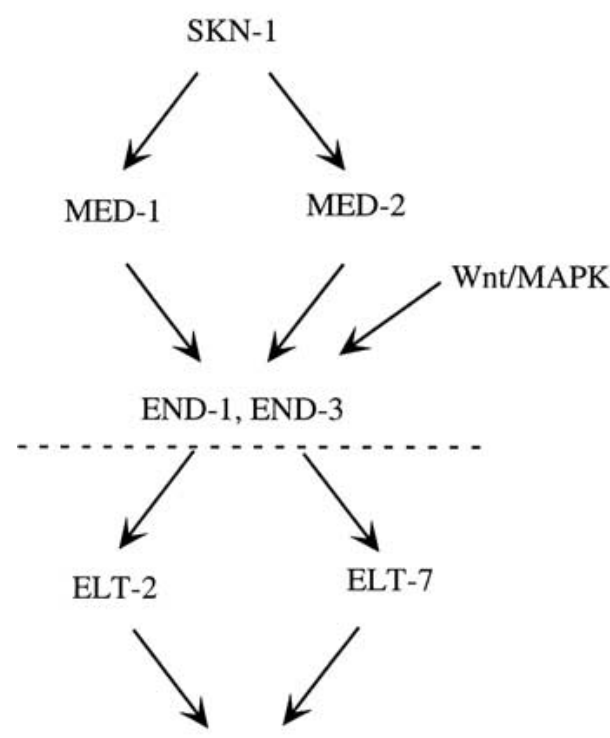

ELT-4
B. Xenopus

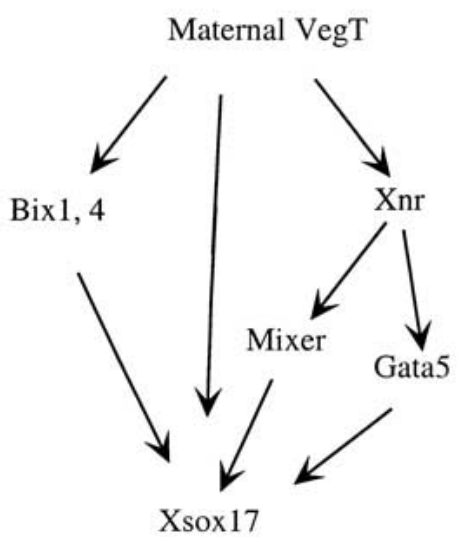

C. Zebrafish

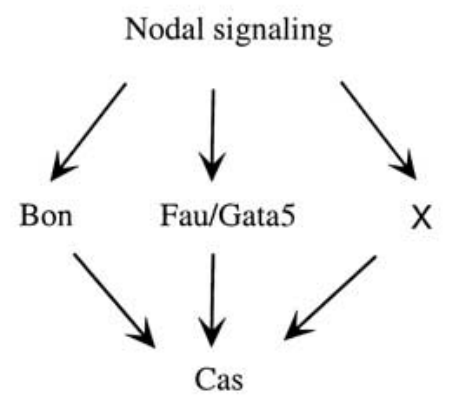

Cas
Nodal signaling

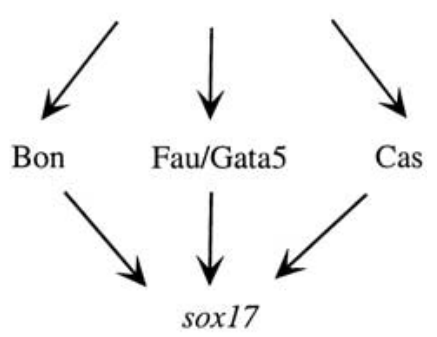

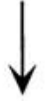

$\operatorname{sox} 17$

Figure 2. Molecular pathways of endoderm formation in Caenorhabditis elegans, Xenopus and zebrafish. (A) In C. elegans, maternal SKN-1 directly activates med expression in the mesendodermal progenitor EMS (Maduro et al. 2001). Subsequently, Wnt/MAPK signaling in E permits the MEDs to activate end-1 and end-3 expression. The ENDs then activate a hypothetical Gata cascade (shown below the dashed line) that has been implicated in endoderm formation. (B) In Xenopus, maternal VegT directly activates Xnr expression (Kofron et al. 1999). Nodal signaling contributes to Mixer and Gata5 expression, which in turn regulate Xsox17 expression (Xanthos et al. 2001). VegT also directly initiates Bix1 and Bix4 expression (Tada et al. 1998; Casey et al. 1999), and has been implicated in initiating Xsox17 expression at the midblastula transition (Engleka et al. 2001). (C) In zebrafish, Nodal signaling regulates the expression of bon, fau/gata5, and cas, and Cas functions downstream of (left), or in parallel to (right), Bon and Fau/Gata5 to regulate sox17 expression. bon encodes a Mix-type transcription factor and cas encodes a Sox-related transcription factor.

the regulatory network involved in endoderm formation in sea urchin is emerging.

Responding to a signal that remains to be identified, $\beta$-catenin accumulates in the nuclei of the mesendodermal progenitors between the 16- and 32-cell stage. There, it forms a complex with TCF and positively regulates the expression of several genes. These genes encode the signaling molecule Wnt8, and several transcription factors including Krox and Krl (a Krüppel-like factor). Krl behaves as a repressor and suppresses animal cell fates (Howard et al. 2001). Wnt8 has been postulated to positively regulate TCF, thereby creating a positive feedback 
loop (Angerer and Angerer 2000). The components of this feedback loop initially contribute to the activation of mesendodermal genes, and later on to the activation of endodermal genes such as gataE, fox $A$, and $f_{0 x} B$. The functional importance of $\beta$-catenin in this early step was demonstrated by overexpressing the cytoplasmic fragment of the transmembrane protein Cadherin which leads to a sequestration of $\beta$-catenin in the cytoplasm (Logan et al. 1999). The roles of Krox and Otx, another early acting mesendodermal transcription factor, were shown through the use of Engrailed repressor (EnR) fusions (Li et al. 1999), and that of Krl through the use of morpholino antisense oligos (Howard et al. 2001).

In a second phase of regulation starting in the late cleavage/early blastula stage, GataE becomes the major endodermal regulator with inputs to many other endodermal genes. The inhibition of gataE translation through the use of morpholino antisense oligos blocks endoderm formation (Davidson et al. 2002). Another endodermal regulator, the Fox/Forkhead family member FoxA, is thought to act as a repressor of itself and its expression is under GataE control. These and other data as well as the emerging regulatory gene network controlling endoderm formation can be found at a frequently updated web site maintained by the Davidson lab at Caltech http://www.its.caltech.edu/ mirsky/endomeso. htm.

The question of how the endoderm segregates from the mesoderm is also being studied in sea urchin and recent data have led to the following model. In the late cleavage/early blastula stage, a subset of cells in the center of the presumptive mesendoderm start to synthesize the Notch ligand Delta as a response to $\beta$-catenin accumulation in their nuclei. Because all mesendodermal progenitors express Notch on their surface, those that are adjacent to the Delta-expressing cells activate their Notch signaling pathway and consequently become mesodermal (Sherwood and McClay 1999; McClay et al. 2000). The mesendodermal progenitors that are not in contact with Delta-expressing cells become endodermal. In addition, there is evidence for a nonautonomous effect of Notch signaling on endoderm formation, possibly through the release of a Wnt signal from the mesodermal cells (Sherwood and McClay 2001). In summary, the convergence of several approaches including systematic promoter dissections as well as various gene inactivation techniques is likely to make the sea urchin an invaluable model system in deciphering the regulatory gene network involved in endoderm formation. The strengths of the sea urchin as an embryological model system should also lead to valuable information regarding the role of these genes in the morphogenetic events associated with endoderm formation.

\section{Endoderm formation in ascidians}

The endodermal tissues of the Ciona larva consist of $\sim 500$ cells whose embryonic lineage is well documented (Conklin 1905; Nishida 1987). At the 32-cell stage, they derive in part from two pairs of vegetal blastomeres whose progeny gives rise exclusively to endodermal tissues. Consistent with this early fate restriction, endodermal progenitors show a high potential for autonomous differentiation when isolated from early embryos (Whittaker 1990; Nishida 1992). This autonomy is dependent on maternal factors that are prelocalized in the egg (Nishida 1993). Endoderm formation in Ciona, as in sea urchin, appears to involve the nuclear accumulation of $\beta$-catenin. Misexpression of $\beta$-catenin in Ciona embryos induces the expression of endodermal genes in cells fated to become notochord and epidermis. Conversely the down-regulation of nuclear $\beta$-catenin by Cadherin overexpression results in the loss of endoderm (Imai et al. 2000). Thus, whereas in sea urchin $\beta$-catenin appears to be involved in the formation of both mesoderm and endoderm, in Ciona, as in C. elegans, it appears to be more specific for endoderm formation. It is possible, however, that in both sea urchin and Ciona initial $\beta$-catenin activity is required for both mesoderm and endoderm formation and that continued $\beta$-catenin activity in certain cells leads to endoderm formation.

Subtractive hybridization screens of mRNAs from embryos overexpressing either $\beta$-catenin or Cadherin has led to the identification of several interesting endodermal genes including an otx gene, an NK-2 class gene, a LIM-homeobox gene, two forkhead genes and a lefty/ antivin gene among others (Satou et al. 2001). The otx gene is expressed in the mesendodermal progenitors of the 32-cell stage embryo. Inhibition of its function by morpholino antisense oligos appears to have no effect on these cells, possibly because of redundant inputs on otx target genes. The NK- 2 class gene, $t t f 1$, is expressed in all endodermal progenitors starting at the 64-cell stage and misexpression of $t t f 1$ leads to ectopic endodermal gene expression suggesting that it plays an important role in endoderm formation (Ristoratore et al. 1999; Satou et al. 2001). Loss-of-function analyses are now required to clarify its role in this process. Notably, the LIM-homeobox gene $1 h x 3$, which is expressed specifically in the endodermal progenitors starting at the 32 -cell stage, is both necessary and sufficient for endoderm formation (Satou et al. 2001). In addition, 1 hx 3 is sufficient to restore endodermal gene expression in the absence of $\beta$-catenin function. These data suggest a model whereby $\beta$-catenin accumulates in the nuclei of the vegetal blastomeres by the 32-cell stage and turns on genes such as otx and $l h \times 3$. These genes in turn, especially $l h \times 3$, initiate a cascade of events that leads to endoderm formation. Of course, because $\beta$-catenin is active in both mesodermal and endodermal progenitors, it will be important to identify the factor(s) responsible for restricting 1 hx 3 expression to the endodermal progenitors.

The compactness of the ascidian genome and relative ease of generating transgenic embryos by electroporation also makes it an attractive organism in which to study cis-regulatory elements (for review, see Corbo et al. 2001). Such work has recently started to explore endoderm formation through the analysis of the $5^{\prime}$-regulatory region of a forkhead/HNF3 $\beta$ gene (DiGregorio et al. 2001). 
In summary, several elements such as $\beta$-catenin, Otx, and Forkhead are present in the regulatory gene networks driving endoderm formation in both sea urchins and ascidians and it is likely that additional ones will emerge. It is also clear from these studies that the combined approach of analyzing both gene function and the control of gene expression in these organisms will continue to generate critical information on the molecular mechanisms regulating endoderm formation.

\section{Endoderm formation in vertebrates}

Our understanding of endoderm formation in vertebrates stems in large part from studies in Xenopus, zebrafish, and mouse. These studies have converged to reveal the importance of the Nodal signaling pathway and a conserved set of transcription factors in this process. Because many of these studies were done concurrently and profoundly influenced one another, some of the following sections are structured around individual factors (or sets of related factors) rather than around individual model systems. In addition, the following sections are ordered temporally, starting with Nodal signaling and ending with members of the Gata and Forkhead families of transcription factors which, as noted above, are implicated in endoderm formation across the phyla.

\section{Nodal signaling}

Nodals are TGF- $\beta$ family members, and at last count include one protein in mouse (Nodal), two in zebrafish (Cyclops [Cyc] and Squint [Sqt]), and five in Xenopus (Xnr1, Xnr2, Xnr4, Xnr5, and Xnr6) (for review, see Whitman 2001). Experiments in Xenopus provided the initial indications that TGF- $\beta$ family members are important for endoderm formation. Subsequent experiments in zebrafish, mouse, and Xenopus showed that Nodal is the TGF- $\beta$ family member critical for this process.

Nodal signaling and zebrafish endoderm formation Genetic studies in zebrafish have shown that cyc and $s q t$ function at least partially redundantly in endoderm formation. Whereas single mutants appear essentially normal in their ability to form endoderm, cyc;sqt double mutants lack all endoderm (Feldman et al. 1998). In addition, overexpression of Antivin, a competitive inhibitor of the Activin/Nodal signaling pathway related to mammalian Lefty (Meno et al. 1999; Thisse and Thisse 1999; Thisse et al. 2000), leads to a complete loss of endoderm (Alexander and Stainier 1999; Thisse and Thisse 1999). Conversely, expression of a constitutively active form of a type-I TGF- $\beta$ receptor is sufficient to induce endodermal gene expression throughout the zebrafish embryo (Alexander and Stainier 1999), and can cell-autonomously divert embryonic cells to an endodermal fate (Peyrieras et al. 1998). Another factor necessary for endoderm formation in zebrafish is Oep, a member of the EGF-CFC family of membrane-associated proteins. Embryos lacking both maternal and zygotic Oep fail to form endoderm and most mesoderm (Zhang et al. 1998a), a phenotype highly reminiscent of the one seen in cyc;sqt double mutants (Feldman et al. 1998). Several lines of evidence, including recent biochemical data, have led to the suggestion that EGF-CFC proteins function as necessary coreceptors for Nodal molecules (Gritsman et al. 1999; Kumar et al. 2001; Yeo and Whitman 2001), and as such would be essential for endoderm formation. However, EGF-CFC proteins such as Oep also appear to have signaling activities of their own (Salomon et al. 1999). For example, the Xenopus EGF-CFC gene $F R L-1$ was isolated on the basis of its ability to induce FGF receptor autophosphorylation in a heterologous yeast expression system (Kinoshita et al. 1995). And the mouse EGF-CFC protein Cripto can bind to murine epithelial cells and lead to increased MAPK phosphorylation (Kannan et al. 1997), though the identity of the receptor complex through which it signals is unknown. Thus, the role of Oep in endoderm formation may extend beyond its function as a Nodal coreceptor. In addition, Nodals were found to be able to heterodimerize with Bmps in the absence of Cripto (Yeo and Whitman 2001), suggesting an EGF-CFC independent mode of action for Nodal molecules.

By the mid-blastula stage, cyc and sqt are expressed in the margin, the region where the blastoderm meets the yolk cell and where the cells fated to become endoderm reside (for review, see Warga and Stainier 2002). The model emerging from these studies is that Nodal molecules trigger a series of events that lead to endoderm formation in cells closest to the source of Nodal secretion. Thus, it has been hypothesized that high levels of Nodal signaling lead to the formation of endoderm and lower levels to the formation of mesoderm. In support of this hypothesis, various genetic and biochemical manipulations that lead to the progressive lowering of Nodal signaling preferentially affect endoderm formation (Schier et al. 1997; Thisse and Thisse 1999). Furthermore, the recent demonstration that Sqt can function as a morphogen during mesoderm formation /Chen and Schier 2001) provides a candidate molecule for this model. Cyc does not appear to share the morphogenetic properties of Sqt, so it will be interesting to further investigate the respective role of these two molecules in endoderm formation. For example, the expression of bonnie and clyde, a transcription factor gene necessary for endoderm formation (see below) is unaffected in cyc mutants but perturbed in sqt mutants (Alexander and Stainier 1999).

The model that the cells closest to the source of Nodal secretion become endodermal is not entirely correct however, as some cells in the marginal zone become mesodermal (Fig. 1E) (Warga and Nüsslein-Volhard 1999). Thus, it is likely that additional signaling pathway(s) influence the endodermal versus mesodermal cell fate decision.

Nodal signaling and mouse endoderm formation The importance of Nodal signaling in mouse endoderm formation comes from several lines of experimental evi- 
dence. The first Nodal gene was in fact identified in mouse through the study of a retroviral insertion that when homozygosed leads to the lack of a primitive streak and most mesoderm as well as an early arrest of embryonic development (Iannaccone et al. 1992; Conlon et al. 1994). Recent analysis of a hypomorphic Nodal allele further shows that Nodal signaling is required for endoderm development, and that higher levels of Nodal signaling appear to be required for endoderm formation than for mesoderm formation (Lowe et al. 2001). In addition, foregut formation appears to require higher levels of Nodal signaling than hindgut formation, although the basis for this difference is not clear. Another line of evidence that Nodal signaling is involved in endoderm formation in mouse comes from the analyses of Cripto mutants which also lack definitive endoderm (Ding et al. 1998).

Nodal signaling and Xenopus endoderm formation In Xenopus, various members of the TGF- $\beta$ family, including Activin, the Nodal family members Xnr-1 and Xnr-2, and Derrière, can induce animal cap cells to express the full range of known embryonic endodermal genes (for review, see Clements et al. 2001). Interfering with TGF- $\beta$ signaling in the embryo's vegetal region from which the endoderm arises (Fig. 1D), using dominant negative forms of Nodal (Osada and Wright 1999), Derrière (Sun et al. 1999), or Activin receptors (Clements et al. 1999; Yasuo and Lemaire 1999; Chang and Hemmati-Brivanlou 2000), reduces endodermal gene expression. These data indicated that TGF- $\beta$ signaling plays an important role in endoderm formation in Xenopus. A critical elaboration of this model came from experiments designed to test various TGF- $\beta$ family members for their ability to restore endodermal gene expression in VegT-depleted embryos. (VegT, which will be covered at greater length in the next section, is a maternally deposited T-box transcription factor required for endoderm formation.) These experiments showed that VegT-regulated TGF- $\beta$ family members such as Xnr1, Xnr2, and Xnr4 as well as derrière are able to restore endodermal gene expression in VegT-depleted embryos (Xanthos et al. 2001). Furthermore, inhibitory forms of Xnr2 and Derrière block the ability of VegT mRNA injections to rescue endodermal gene expression in VegT-depleted embryos. These experiments clearly establish a central role for TGF- $\beta$ signaling in endoderm formation in Xenopus, although determining the exact role of individual TGF- $\beta$ family members will require more specific loss-of-function approaches. In addition, examining the relative amount of phosphorylated Smad2 in various regions of the embryo indicated that higher levels of Nodal signaling are present vegetally (Faure et al. 2000). These data are consistent with the earlier stated proposal that higher levels of Nodal signaling lead to endoderm formation while lower levels lead to mesoderm formation. Admittedly, this hypothesis needs to be tested further not only in Xenopus but also in mouse and zebrafish.

In summary, Nodal signaling appears to be central to endoderm formation in vertebrates and it will be inter- esting to determine whether TGF- $\beta$ signaling plays any role in endoderm formation in more primitive organisms such as sea urchins and ascidians.

\section{Regulators of Nodal expression}

A turning point in the molecular analysis of Xenopus endoderm formation was the demonstration that VegT is a vegetally localized endodermal determinant (Zhang et al. 1998b). In fact, VegT is both necessary and sufficient for endoderm formation (Lustig et al. 1996; Stennard et al. 1996; Zhang and King 1996; Horb and Thomsen 1997; Zhang et al. 1998b; Xanthos et al. 2001). VegT regulates the expression of TGF- $\beta$ family members such as $X n r 1$, Xnr2, and Xnr4 as well as Derrière (Kofron et al. 1999; Hyde and Old 2000). It also appears to regulate directly the expression of Mix-type homeobox genes such as Bix1 and Bix4 (Tada et al. 1998; Casey et al. 1999), and possibly the activation of the endodermal determinant Sox17 (Clements et al. 1999; Yasuo and Lemaire 1999; Engleka et al. 2001). Thus, VegT appears to regulate endoderm formation in several ways, principally by controlling Nodal gene expression, and also by directly activating transcriptional regulators of endoderm formation (Fig. 2B). In turn, Nodal signals activate the zygotic expression of $V e g T$, as well as maintain their own expression, thereby establishing a positive feedback loop for the initiation and maintenance of endodermal gene expression in vegetal cells (for review, see Clements et al. 2001).

Several T-box transcription factor genes have been identified and analyzed genetically in zebrafish and mouse. In mouse, the T-box gene Eomesodermin is expressed from an early stage in extraembryonic ectoderm, the tissue that initially induces Nodal expression in the adjacent epiblast cells (Russ et al. 2000; Brennan et al. 2001), and Eomesodermin mutants, like Nodal mutants, fail to form mesoderm and definitive endoderm. These data suggest that Eomesodermin could be part of the regulatory network controlling Nodal expression in the early mouse embryo, either directly or indirectly.

In zebrafish, Spadetail, a homolog of VegT (Griffin et al. 1998), appears not to regulate nodal or sox17 expression, while an Eomesodermin homolog is first expressed during somitogenesis in the presumptive telencephalon (Mione et al. 2001). Thus, zebrafish Nodal expression could be under the control of an as yet unidentified $\mathrm{T}$ box factor, or even another type of transcription factor. Alternatively, endoderm formation could be induced by maternal Nodal molecules (sqt is expressed maternally; Feldman et al. 1998), thereby bypassing the need for spatially restricted transcriptional regulators. In the context of discussing the role of T-box transcription factors in endoderm formation, it is also interesting to mention that in ascidians, endodermal expression of a forkhead/ HNF3 $\beta$ gene is under the control of the T-box protein VegTR (DiGregorio et al. 2001).

\section{Effectors of Nodal signaling}

Smads Nodal binding to its receptor complex leads to the phosphorylation of Smad2 (and possibly also Smad3), 
which translocates to the nucleus and together with other proteins, activates transcription. Smad2 mutant mice lack all derivatives of the embryonic germ layers consistent with Smad2 playing an essential role in Nodal signaling (Nomura and Li 1998; Waldrip et al. 1998; Weinstein et al. 1998; Heyer et al. 1999). However, chimeric studies have been key to understanding the cellautonomous role of Smad2 in embryonic development: They have shown that Smad2 mutant cells can extensively colonize ectodermal and mesodermal lineages but are excluded from the definitive endodermal lineage during gastrulation (Tremblay et al. 2000). These experiments indicate that Smad2 is a key Nodal effector that is essential for endoderm formation. Smad3 may compensate for the loss of Smad2 during mesoderm formation (Tremblay et al. 2000).

FoxH1 Smad2 partners include the Forkhead protein FoxH1/Fast. FoxH1 was initially identified in Xenopus through its ability to bind an activin response element in the promoter region of the mesendodermal gene Mix.2 (Chen et al. 1996). Mutations in the mouse FoxH1 gene block endoderm formation (Hoodless et al. 2001; Yamamoto et al. 2001), although in chimeric embryos a few FoxH1 mutant cells contributed to the most anterior region of the foregut (Hoodless et al. 2001). Smad2 mutant cells can similarly populate the most anterior region of the foregut (Tremblay et al. 2000). These data are in apparent contradiction with the report that foregut formation requires higher levels of Nodal signaling than hindgut formation (Lowe et al. 2001). However, because of the convergence of many different cell types to the anterior foregut region, more detailed studies are needed to determine the exact role Nodal signaling plays in their development.

In Xenopus and zebrafish, FoxH1 appears to be required for formation of some of the mesoderm but not the endoderm (Watanabe and Whitman 1999; Pogoda et al. 2000; Sirotkin et al. 2000), suggesting that additional Smad2 partner(s) essential for endoderm formation remain to be identified. Alternatively, Smad2 and/or Smad3 might in some cell contexts be able to function without a partner.

Mix-type factors Certain members of the Mix family of paired-class homeodomain transcription factors can also bind phosphorylated Smad2. This family comprises at least one member in mouse, Mml (Pearce and Evans 1999; Robb et al. 2000), three in zebrafish, Bonnie and clyde (Bon) (Alexander et al. 1999; Kikuchi et al. 2000) and Mtx1 and 2 (Hirata et al. 2000), and seven in Xenopus (Rosa 1989; Mead et al. 1996; Vize 1996; Ecochard et al. 1998; Henry and Melton 1998; Lemaire et al. 1998; Tada et al. 1998). The binding of these factors to activated Smad2 occurs through a short motif that is also present in the Forkhead protein FoxH1 (Germain et al. 2000). The founding member of the Mix family, Mix.1, is an endodermally expressed gene initially identified because of its responsiveness to mesodermal inducers (Rosa 1989), and subsequently implicated in endoderm formation (Lemaire et al. 1998). One of the most comprehensive studies on a Xenopus Mix genes and endoderm formation was carried out on Mixer (Henry and Melton 1998). Mixer is expressed exclusively in endodermal precursors starting at the beginning of gastrulation and can activate endodermal gene expression in animal cap cells. In addition, dominant interference studies with a Mixer-EnR chimera indicate that it plays a role in the regulation of endodermal gene expression, and that it acts upstream of the endodermal determinant Sox 17. However, because Mixer expression initiates after the onset of Sox17 expression, it has been suggested that Mixer functions to maintain endodermal Sox17 expression (Fig. 2B).

Molecular and genetic analyses in zebrafish have clearly established that the Mix family member Bon functions upstream of Sox17: bon expression precedes the onset of sox17 expression (Alexander and Stainier 1999|, and bon mutants lack $90 \%$ of their endodermal cells, as assessed by sox17 expression (Kikuchi et al. 2000). Furthermore, Bon requires the function of the novel Sox protein Cas (see below) to induce sox17 expression and endoderm formation (Fig. 2C) (Alexander and Stainier 1999; Dickmeis et al. 2001; Kikuchi et al. 2001).

In mouse, the Mix gene, Mml, which interestingly lacks a Smad interaction motif, is expressed in the nascent primitive streak (Pearce and Evans 1999; Robb et al. 2000) where the endoderm and mesoderm originate (Fig. 1F) and thus might play a role in the formation of these germ layers. However, and at first glance, $\mathrm{Mml}$ does not appear to be the mouse bon ortholog based on synteny considerations and the observations that $\mathrm{Mml}$ lacks a Smad interaction motif and can not rescue the endodermal defect in bon mutants (L. Trinh and D.Y.R. Stainier, unpubl.). Thus, it is possible that the mouse genome contains additional Mix-type genes.

As noted earlier, certain members of the Mix family, including Mixer (Germain et al. 2000) and Bon (Randall et al. 2002), can interact with phosphorylated Smad2 and could help transduce the Nodal signal. However, in Xenopus and zebrafish, Mixer and bon expression are initially induced by Nodal signaling suggesting that another Nodal effector is initially required to partner with phosphorylated Smad2 to activate Mixer and bon expression. In Xenopus, FoxH1 is a likely regulator of Mixer expression as the Mixer promoter contains a FoxH1 binding site (L. Henry and M. Whitman, pers. comm.), and it will be interesting to determine the relationship between FoxH1 and bon in zebrafish.

\section{Other signaling pathways involved in endoderm formation}

Although Nodal signaling appears to play a central role in vertebrate endoderm formation, other signaling pathways have also been implicated.

\section{Bmp signaling}

Overexpression of the Bmp antagonists Chordin and Noggin has been reported to promote endodermal gene 
expression in Xenopus animal cap explants (Sasai et al. 1996), suggesting that high levels of Bmp signaling may inhibit endoderm formation. Because Nodal and Bmp can form inactive heterodimers (Yeo and Whitman 2001), overexpressing Chordin, which itself binds Bmp with relatively high affinity, might possibly lead to the release of Nodal molecules and the activation of Nodal signaling, thereby inducing endoderm. Zebrafish embryos lacking Bmp2b or Bmp7 function exhibit a greater number and expanded distribution of endodermal precursors at the end of gastrulation, whereas embryos lacking Chordin function have fewer endodermal precursors (Warga and Stainier 2002). These observations are in agreement with lineage tracing data that show that more endoderm is derived from dorsal than ventral regions of the late blastula (Warga and Nüsslein-Volhard 1999). Together, these data suggest that Bmp signaling may also participate in endoderm formation and patterning, although clearly more work is needed to understand whether this potential Bmp function occurs via inhibition of Nodal signaling or through some other mechanism.

\section{Wht signaling}

In C. elegans, as well as in sea urchins and ascidians, Wnt signaling and/or its transcriptional effectors such as $\beta$-catenin appear to play important roles in endoderm formation. In vertebrates such as Xenopus and zebrafish, $\beta$-catenin has been shown to play a key role in patterning the early embryo (Heasman et al. 2000; Kelly et al. 2000) and it will be important to determine whether it is also involved in endoderm formation.

\section{Other transcription factors involved in vertebrate endoderm formation}

\section{Gata factors}

The zinc finger transcriptional activators of the Gata family have been implicated in endoderm formation in C. elegans, Drosophila, and sea urchins, as mentioned earlier in this review. Some of their vertebrate counterparts have also been implicated in this process. Vertebrate genomes contain at least six evolutionarily conserved gata genes. Although gata1, gata2, and gata3 function predominantly in hematopoietic development (for review, see Orkin and Zon 1997), gata4, gata5, and gata6 are expressed in extraembryonic tissues, heart, and endoderm (for review, see Charron and Nemer 1999). Studies of endodermal gene regulation have suggested the involvement of Gata factors: transfection of nonendodermal cells with gata genes induces the transcription of endodermal genes such as IFABP, gastric $\mathrm{H+} / \mathrm{K+-}$ ATPase and HNF4 (Maeda et al. 1996; Gao et al. 1998; Morrisey et al. 1998). Direct regulation of endodermal genes by Gata factors has been further suggested by a study demonstrating occupation of a gata motif in the albumin promoter in mouse embryonic endodermal cells
(Bossard and Zaret 1998). In addition, the C. elegans Gata factor END-1 was shown to be a potent activator of endoderm formation in Xenopus animal caps (Shoichet et al. 2000).

Genetic demonstration of the role of a vertebrate gata gene in endoderm formation has come from the analysis of the zebrafish faust (fau) mutation. fau encodes zebrafish Gata5 and is required for endoderm formation upstream of sox17 (Reiter et al. 1999, 2001). In addition, fau/gata5 is sufficient to induce sox17 expression and requires the function of the novel Sox protein Cas to do so (Kikuchi et al. 2001; Reiter et al. 2001). Initial expression of fau/gata5, like that of bon, is regulated by Nodal signaling (Alexander and Stainier 1999; Rodaway et al. 1999; Reiter et al. 2001). Similarly, in Xenopus, gata5 is induced by Nodal signaling and is sufficient, as is gata4, to induce endoderm (Weber et al. 2000). Genetic analyses in mouse have so far failed to reveal a clear role for gata4, gata5, or gata6 in endoderm formation, despite their widespread and early expression in this tissue (for review, see Molkentin 2000). It is expected that tissue specific gene inactivation and/or the simultaneous inactivation of several of these genes will reveal their likely role in this process. As mentioned earlier, the Drosophila gata gene serpent has been implicated in both morphogenesis and cell differentiation. Similarly, in zebrafish, fau/gata5 appears to play multiple roles in endoderm morphogenesis and differentiation (Reiter et al. 1999, 2001), and it will be interesting to investigate who the downstream effectors of Gata function are and how they regulate these highly intertwined processes.

\section{Sox factors}

Sox factors are transcriptional regulators that contain a high mobility group (HMG) DNA-binding domain, and they were first implicated in endoderm formation from work in Xenopus: Hudson et al. (1997) identified Sox17 in a search for genes enriched in endodermal progenitors. Overexpression of Sox17 promotes endodermal gene expression in animal cap explants, whereas expression of a Sox17-EnR chimera inhibits endoderm differentiation in both isolated vegetal pole explants and the intact embryo. Expressing Sox17 in cells fated to become ectoderm causes their descendants either to relocate into the embryonic gut or to die at a late developmental stage, whereas disrupting Sox17 activity in cells fated to become endoderm causes them to enter mesodermal or ectodermal lineages (Clements and Woodland 2000). These data indicate that Sox 17 plays a critical role in endoderm formation in Xenopus.

Endodermally-expressed sox genes have also been isolated in zebrafish. sox17 is expressed specifically in endodermal precursors at the onset of gastrulation, although its function is not known. A novel member of the same SoxF subfamily has recently been determined to be encoded by the casanova (cas) gene (Dickmeis et al. 2001; Kikuchi et al. 2001). cas mutants completely lack sox17 expression indicating that cas plays a critical role early in the formation of the endodermal lineage (Alex- 
ander et al. 1999; Alexander and Stainier 1999). Furthermore, and as noted earlier, Cas function is necessary for the ability of Bon and Fau/Gata5 to induce sox17 expression and endoderm formation (Alexander and Stainier 1999; Reiter et al. 2001). cas expression, like that of bon and fau/gata5, is regulated by Nodal signaling, and cas is sufficient to restore endoderm in bon and fau/gata5 mutants. These data have led to a model whereby, in zebrafish, Nodal signaling regulates the expression of bon, fau/gata5, and cas, and Cas functions downstream of, or in parallel to, Bon and Fau/Gata5 to regulate sox17 expression and endoderm formation (Fig. 2C) (Alexander and Stainier 1999; Kikuchi et al. 2001). Cas was also shown to be sufficient to drive cells fated to become mesoderm to populate the gut. However, this transfating ability appears to be restricted to the mesoderm and does not extend to the ectoderm /unlike what is seen with ectopic expression of Sox17 in Xenopus; Clements and Woodland 2000). Conversely, in the absence of Cas function, cells fated to the endodermal lineage become mesodermal (Dickmeis et al. 2001).

Mouse Sox17 was originally identified as a stage-specific transcriptional regulator during mouse spermatogenesis (Kanai et al. 1996). A detailed analysis of its expression pattern has more recently revealed an earlier phase of expression in the visceral and definitive endoderm of the postimplantation embryo (Kanai-Azuma et al. 2002). Although the SoxF genes Sox17 and Sox7 are both expressed in the visceral endoderm, Sox17 but not Sox7 is expressed in the endoderm of the embryonic gut. Sox17 mutant embryos show profound deficits in gut endoderm formation and chimeric analysis shows that Sox17 mutant cells contribute extensively to ectodermal and mesodermal tissues, but are excluded from mid- and hind-gut endoderm (Kanai-Azuma et al. 2002). Interestingly, Sox17 mutant cells, like FoxH1 and Smad2 mutant cells, can contribute to some extent to the foregut endoderm. Thus, it appears that in all vertebrates thus far examined, a SoxF transcription factor plays a key role in endoderm formation.

\section{Forkhead factors}

As noted earlier, Forkhead genes have been implicated in endoderm formation in all model systems examined to date. At least three vertebrate Forkhead genes are expressed during endoderm formation, FoxA1/HNF3 $\alpha /$ fkd7, FoxA2/HNF3ß/axial, and FoxA3/HNF3y/fkd2 (Sasaki and Hogan 1993; Odenthal and Nüsslein-Volhard 1998; Warga and Nüsslein-Volhard 1999). The function of these genes has been analyzed genetically in mouse. FoxA1 and FoxA3 mutants do not show an early endodermal phenotype (Kaestner et al. 1998, 1999), probably because of overlap in expression pattern and functional compensation. However, FoxA2, which comes on in endodermal precursors at the onset of gastrulation in both mouse and zebrafish, is essential for mouse foregut and midgut but not hindgut development (Ang et al. 1993; Weinstein et al. 1994; Dufort et al. 1998). Interestingly, in late gastrula stage zebrafish embryos, FoxA2 expression appears to be missing from the cells that give rise to the hindgut (Alexander and Stainier 1999) providing a possible explanation for the dispensability of its function in mouse hindgut development. This expression pattern also indicates that anterioposterior patterning of the endoderm is already manifest during gastrulation stages.

Smad2 binding elements are present in the Xenopus FoxA2 promoter (Howell and Hill 1997), suggesting that its expression is controlled by Nodal signaling. However, in zebrafish, foxA2 expression, unlike that of cas, bon, and fau/gata5, is not an immediate early response to Nodal signaling (Alexander and Stainier 1999) suggesting that other transcriptional regulators play critical roles in the timing of its activation. Alternatively, as is the case with PHA-4 and its target genes in C. elegans (Gaudet and Mango 2002), the relative affinity of Nodal effectors for their various binding sites could determine the onset of expression of the corresponding target genes. According to this model, the cas, bon, and fau/gata 5 promoters would have high affinity sites for Nodal effectors whereas the later expressed foxA2 (and sox17) gene(s) would have low affinity sites.

\section{Summary}

The formation of an ancient tissue like the endoderm is expected to utilize common molecular pathways across the phyla, and the studies so far point in that very direction (Table 1). However, this comparative analysis also points to clear gaps in our knowledge, such as the poten-

Table 1. Signaling pathways and transcriptional effectors involved in endoderm formation

\begin{tabular}{|c|c|c|c|c|c|c|}
\hline & Wnt/ $\beta$-catenin & Nodal $^{a}$ & Mix-type & Gata & Sox & Forkhead \\
\hline C. elegans & yes $^{\mathrm{b}}$ & n.d. & n.d. & yes $^{\mathrm{b}}$ & n.d. & yes \\
\hline Drosophila & n.d. ${ }^{\mathrm{c}}$ & n.d. & n.d. & yes $^{\mathrm{b}}$ & n.d. & $y^{b} s^{b}$ \\
\hline Sea urchin & yes $^{\mathrm{b}}$ & n.d. & n.d. & $y_{e s}{ }^{b}$ & n.d. & yes \\
\hline Ascidians & yes $^{b}$ & n.d. & n.d. & yes & n.d. & yes \\
\hline Xenopus & n.d. & yes $^{\mathrm{b}}$ & yes $^{\mathrm{b}}$ & $y_{e s}^{b}$ & yes $^{\mathrm{b}}$ & yes \\
\hline Zebrafish & n.d. & yes $^{\mathrm{b}}$ & yes $^{\mathrm{b}}$ & $y_{e s}{ }^{b}$ & yes $^{\mathrm{b}}$ & yes \\
\hline Mouse & n.d. & yes $^{b}$ & yes & yes & yes $^{b}$ & yes $^{b}$ \\
\hline
\end{tabular}

${ }^{\mathrm{a} A n d}$ its effectors Smad2 and FoxH1.

${ }^{\mathrm{b}}$ Functionally implicated.

${ }^{\mathrm{c}}$ Functionally implicated in hindgut formation (an ectodermal derivative). 
tial role of TGF- $\beta$ signaling in endoderm formation in more primitive organisms and that of Wnt signaling in vertebrates. In the next several years, we can expect a rapid elucidation of these questions, as well the continuing investigation of more complex issues, such as how the various endodermal organs form. Equally exciting will be attempts to coax stem cells to form endodermal tissue, a likely prerequisite to forming endodermal organs such as the pancreas and liver de novo.

\section{Acknowledgments}

I thank Malcolm Whitman, Joel Rothman, Rachel Warga, Jon Alexander, Janet Heasman, Jeremy Reiter, Le Trinh, Pia Aanstadt, Xin Sun, Eric Davidson, Dave McClay, Andy Ransick, Susan Mango, Lynne Angerer, and Steve Beckendorf for discussions and/or critical reading of the manuscript. Rachel Warga also provided the inspiration for the title, Felix Aburto helped with the references, and Kathy Jee with Figure 1. Our work on endoderm formation has been supported by grants from the NIH (NIDDK) as well as the Packard Foundation.

\section{References}

Alexander, J. and Stainier, D.Y.R. 1999. A molecular pathway leading to endoderm formation in zebrafish. Curr. Biol. 9: $1147-1157$.

Alexander, J., Rothenberg, M., Henry, G.L., and Stainier, D.Y. 1999. casanova plays an early and essential role in endoderm formation in zebrafish. Dev. Biol. 215: 343-357.

Ang, S.L., Wierda, A., Wong, D., Stevens, K.A., Cascio, S., Rossant, J., and Zaret, K.S. 1993. The formation and maintenance of the definitive endoderm lineage in the mouse: Involvement of HNF3/forkhead proteins. Development 119: 1301-1315.

Angerer, L.M. and Angerer, R.C. 2000. Animal-vegetal axis patterning mechanisms in the early sea urchin embryo. Dev. Biol. 218: 1-12.

Azzaria, M., Goszczynski, B., Chung, M.A., Kalb, J.M., and McGhee, J.D. 1996. A fork head/HNF-3 homolog expressed in the pharynx and intestine of the Caenorhabditis elegans embryo. Dev. Biol. 178: 289-303.

Bienz, M. 1997. Endoderm induction in Drosophila: The nuclear targets of the inducing signals. Curr. Opin. Genet. Dev. 7: 683-688.

Bossard, P. and Zaret, K.S. 1998. GATA transcription factors as potentiators of gut endoderm differentiation. Development 125: 4909-4917.

Bowerman, B., Eaton, B.A., and Priess, J.R. 1992. skn-1, a maternally expressed gene required to specify the fate of ventral blastomeres in the early C. elegans embryo. Cell 68: 10611075.

Brennan, J., Lu, C.C., Norris, D.P., Rodriguez, T.A., Beddington, R.S., and Robertson, E.J. 2001. Nodal signalling in the epiblast patterns the early mouse embryo. Nature 411: 965969.

Bronner, G., Chu-LaGraff, Q., Doe, C.Q., Cohen, B., Weigel, D., Taubert, H., and Jackle, H. 1994. Sp1/egr-like zinc-finger protein required for endoderm specification and germ-layer formation in Drosophila. Nature 369: 664-668.

Calvo, D., Victor, M., Gay, F., Sui, G., Luke, M.P., Dufourcq, P., Wen, G., Maduro, M., Rothman, J., and Shi, Y. 2001. A POP-1 repressor complex restricts inappropriate cell typespecific gene transcription during Caenorhabditis elegans embryogenesis. EMBO I. 20: 7197-7208.

Casey, E.S., Tada, M., Fairclough, L., Wylie, C.C., Heasman, J., and Smith, J.C. 1999. Bix4 is activated directly by VegT and mediates endoderm formation in Xenopus development. Development 126: 4193-4200.

Chang, C. and Hemmati-Brivanlou, A. 2000. A post-mid-blastula transition requirement for TGF $\beta$ signaling in early endodermal specification. Mech. Dev. 90: 227-235.

Charron, F. and Nemer, M. 1999. GATA transcription factors and cardiac development. Semin. Cell. Dev. Biol. 10: 85-91.

Chen, X., Rubock, M.J., and Whitman, M. 1996. A transcriptional partner for MAD proteins in TGF- $\beta$ signalling. Nature 383: 691-696.

Chen, Y. and Schier, A.F. 2001. The zebrafish Nodal signal Squint functions as a morphogen. Nature 411: 607-610.

Clements, D. and Woodland, H.R. 2000. Changes in embryonic cell fate produced by expression of an endodermal transcription factor, Xsox17. Mech. Dev. 99: 65-70.

Clements, D., Friday, R.V., and Woodland, H.R. 1999. Mode of action of VegT in mesoderm and endoderm formation. Development 126: 4903-4911.

Clements, D., Rex, M., and Woodland, H.R. 2001. Initiation and early patterning of the endoderm. Int. Rev. Cytol. 203: 383446.

Conklin, E.G. 1905. The organization and cell lineage of the ascidian egg. J. Acad. Nat. Sci. 13: 1-119.

Conlon, F.L., Lyons, K.M., Takaesu, N., Barth, K.S., Kispert, A., Herrmann, B., and Robertson, E.J. 1994. A primary requirement for Nodal in the formation and maintenance of the primitive streak in the mouse. Development 120: 19191928.

Corbo, J.C., Di Gregorio, A., and Levine, M. 2001. The ascidian as a model organism in developmental and evolutionary biology. Cell 106: 535-538.

Davidson, E.H., Rast, J.P., Oliveri, P., Ransick, A., Calestani, C., Yuh, C.H., Minokawa, T., Amore, G., Hinman, V., ArenasMena, C., et al. 2002. A genomic regulatory network for development. Science 295: 1669-1678.

Dickmeis, T., Mourrain, P., Saint-Etienne, L., Fischer, N., Aanstad, P., Clark, M., Strahle, U., and Rosa, F. 2001. A crucial component of the endoderm formation pathway, casanova, is encoded by a novel sox-related gene. Genes \& Dev. 15: $1487-1492$

DiGregorio, A., Corbo, J.C., and Levine, M. 2001. The regulation of forkhead/HNF-3 $\beta$ expression in the Ciona embryo. Dev. Biol. 229: 31-43.

Ding, J., Yang, L., Yan, Y.T., Chen, A., Desai, N., WynshawBoris, A., and Shen, M.M. 1998. Cripto is required for correct orientation of the anterior-posterior axis in the mouse embryo. Nature 395: 702-707.

Dufort, D., Schwartz, L., Harpal, K., and Rossant, J. 1998. The transcription factor $H N F 3 \beta$ is required in visceral endoderm for normal primitive streak morphogenesis. Development 125: 3015-3025.

Ecochard, V., Cayrol, C., Rey, S., Foulquier, F., Caillol, D., Lemaire, P., and Duprat, A. M. 1998. A novel Xenopus mix-like gene milk involved in the control of the endomesodermal fates. Development 125: 2577-2585.

Engleka, M.J., Craig, E.J., and Kessler, D.S. 2001. VegT activation of Sox17 at the midblastula transition alters the response to nodal signals in the vegetal endoderm domain. Dev. Biol. 237: 159-172.

Faure, S., Lee, M.A., Keller, T., ten Dijke, P., and Whitman, M. 2000. Endogenous patterns of TGF $\beta$ superfamily signaling during early Xenopus development. Development 127: 2917-2931. 
Feldman, B., Gates, M.A., Egan, E.S., Dougan, S.T., Rennebeck, G., Sirotkin, H.I., Schier, A.F., and Talbot, W.S. 1998. Zebrafish organizer development and germ-layer formation require nodal-related signals. Nature 395: 181-185.

Fukushige, T., Hawkins, M.G., and McGhee, J.D. 1998. The GATA-factor elt-2 is essential for formation of the Caenorhabditis elegans intestine. Dev. Biol. 198: 286-302.

Gao, X., Sedgwick, T., Shi, Y.B., and Evans, T. 1998. Distinct functions are implicated for the GATA-4, -5 , and -6 transcription factors in the regulation of intestine epithelial cell differentiation. Mol. Cell. Biol. 18: 2901-2911.

Gaudet, J. and Mango, S.E. 2002. Regulation of organogenesis by the C. elegans FoxA protein PHA-4. Science 295: 821-825.

Germain, S., Howell, M., Esslemont, G.M., and Hill, C.S. 2000 Homeodomain and winged-helix transcription factors recruit activated Smads to distinct promoter elements via a common Smad interaction motif. Genes \& Dev. 14: 435451.

Griffin, K.J., Amacher, S.L., Kimmel, C.B., and Kimelman, D. 1998. Molecular identification of spadetail: Regulation of zebrafish trunk and tail mesoderm formation by T-box genes. Development 125: 3379-3388.

Gritsman, K., Zhang, J., Cheng, S., Heckscher, E., Talbot, W.S., and Schier, A.F. 1999. The EGF-CFC protein One-eyed pinhead is essential for nodal signaling. Cell 97: 121-132.

Hayes, S.A., Miller, J.M., and Hoshizaki, D.K. 2001. serpent, a GATA-like transcription factor gene, induces fat-cell development in Drosophila melanogaster. Development 128: 1193-1200.

Heasman, J., Kofron, M., and Wylie, C. 2000. $\beta$-catenin signaling activity dissected in the early Xenopus embryo: A novel antisense approach. Dev. Biol. 222: 124-134.

Henry, G.L. and Melton, D.A. 1998. Mixer, a homeobox gene required for endoderm development. Science 281: 91-96.

Heyer, J., Escalante-Alcalde, D., Lia, M., Boettinger, E., Edelmann, W., Stewart, C.L., and Kucherlapati, R. 1999. Postgastrulation Smad2-deficient embryos show defects in embryo turning and anterior morphogenesis. Proc. Natl. Acad. Sci. 96: $12595-12600$

Hirata, T., Yamanaka, Y., Ryu, S.L., Shimizu, T., Yabe, T., Hibi, M., and Hirano, T. 2000. Novel mix-family homeobox genes in zebrafish and their differential regulation. Biochem. Biophys. Res. Commun. 271: 603-609.

Hoodless, P.A., Pye, M., Chazaud, C., Labbe, E., Attisano, L., Rossant, J., and Wrana, J.L. 2001. FoxH1 (Fast) functions to specify the anterior primitive streak in the mouse. Genes \& Dev. 15: 1257-1271.

Horb, M.E. and Thomsen, G.H. 1997. A vegetally localized Tbox transcription factor in Xenopus eggs specifies mesoderm and endoderm and is essential for embryonic mesoderm formation. Development 124: 1689-1698.

Horner, M.A., Quintin, S., Domeier, M.E., Kimble, J., Labouesse, M., and Mango, S.E. 1998. pha-4, an HNF-3 homolog, specifies pharyngeal organ identity in Caenorhabditis elegans. Genes \& Dev. 12: 1947-1952.

Howard, E.W., Newman, L.A., Oleksyn, D.W., Angerer, R.C., and Angerer, L.M. 2001. SpKrl: A direct target of $\beta$-catenin regulation required for endoderm differentiation in sea urchin embryos. Development 128: 365-375.

Howell, M. and Hill, C.S. 1997. XSmad2 directly activates the activin-inducible, dorsal mesoderm gene XFKH1 in Xenopus embryos. EMBO J. 16: 7411-7421.

Hudson, C., Clements, D., Friday, R.V., Stott, D., and Woodland, H.R. 1997. Xsox $17 \alpha$ and $-\beta$ mediate endoderm formation in Xenopus. Cell 91: 397-405.

Hyde, C.E. and Old, R.W. 2000. Regulation of the early expres- sion of the Xenopus nodal-related 1 gene, Xnr1. Development 127: 1221-1229.

Iannaccone, P.M., Zhou, X., Khokha, M., Boucher, D., and Kuehn, M.R. 1992. Insertional mutation of a gene involved in growth regulation of the early mouse embryo. Dev. Dyn. 194: $198-208$

Imai, K., Takada, N., Satoh, N., and Satou, Y. 2000. (beta)catenin mediates the specification of endoderm cells in ascidian embryos. Development 127: 3009-3020.

Kaestner, K.H., Hiemisch, H., and Schutz, G. 1998. Targeted disruption of the gene encoding hepatocyte nuclear factor $3 \gamma$ results in reduced transcription of hepatocyte-specific genes. Mol. Cell. Biol. 18: 4245-4251.

Kaestner, K.H., Katz, J., Liu, Y., Drucker, D.J., and Schutz, G. 1999. Inactivation of the winged helix transcription factor HNF3 $\alpha$ affects glucose homeostasis and islet glucagon gene expression in vivo. Genes \& Dev. 13: 495-504.

Kaestner, K.H., Knochel, W., and Martinez, D.E. 2000. Unified nomenclature for the winged helix/forkhead transcription factors. Genes \& Dev. 14: 142-146.

Kalb, J.M., Lau, K.K., Goszczynski, B., Fukushige, T., Moons, D., Okkema, P.G., and McGhee, J.D. 1998. pha-4 is Ce-fkh-1, a fork head/HNF- $3 \alpha, \beta, \gamma$ homolog that functions in organogenesis of the C. elegans pharynx. Development 125: 21712180.

Kanai, Y., Kanai-Azuma, M., Noce, T., Saido, T.C., Shiroishi, T., Hayashi, Y., and Yazaki, K. 1996. Identification of two Sox17 messenger RNA isoforms, with and without the high mobility group box region, and their differential expression in mouse spermatogenesis. J. Cell. Biol. 133: 667-681.

Kanai-Azuma, M., Kanai, Y., Gad, J.M., Tajima, Y., Taya, C., Kurohmaru, M., Sanai, Y., Yonekawa, H., Yazaki, K., Tam, P., and Hayashi, Y. 2002. Depletion of definitive gut endoderm in Sox17-null mutant mice. Development (in press).

Kannan, S., De Santis, M., Lohmeyer, M., Riese II, D.J., Smith, G.H., Hynes, N., Seno, M., Brandt, R., Bianco, C., Persico, G., et al. 1997. Cripto enhances the tyrosine phosphorylation of Shc and activates mitogen-activated protein kinase (MAPK) in mammary epithelial cells. J. Biol. Chem. 272: 3330-3335.

Kelly, C., Chin, A.J., Leatherman, J.L., Kozlowski, D.J., and Weinberg, E.S. 2000. Maternally controlled b-catenin-mediated signaling is required for organizer formation in the zebrafish. Development 127: 3899-3911.

Kikuchi, Y., Trinh, L.A., Reiter, J.F., Alexander, J., Yelon, D., and Stainier, D.Y. 2000. The zebrafish bonnie and clyde gene encodes a Mix family homeodomain protein that regulates the generation of endodermal precursors. Genes \& Dev. 14: 1279-1289.

Kikuchi, Y., Agathon, A., Alexander, J., Thisse, C., Waldron, S. Yelon, D., Thisse, B., and Stainier, D.Y. 2001. casanova encodes a novel Sox-related protein necessary and sufficient for early endoderm formation in zebrafish. Genes \& Dev. 15: 1493-1505.

Kinoshita, N., Minshull, J., and Kirschner, M.W. 1995. The identification of two novel ligands of the FGF receptor by a yeast screening method and their activity in Xenopus development. Cell 83: 621-630.

Kofron, M., Demel, T., Xanthos, J., Lohr, J., Sun, B., Sive, H., Osada, S., Wright, C., Wylie, C., and Heasman, J. 1999. Mesoderm induction in Xenopus is a zygotic event regulated by maternal VegT via TGF $\beta$ growth factors. Development 126: 5759-5770.

Kumar, A., Novoselov, V., Celeste, A.J., Wolfman, N.M., ten Dijke, P., and Kuehn, M.R. 2001. Nodal signaling uses activin and transforming growth factor- $\beta$ receptor-regulated Smads. J. Biol. Chem. 276: 656-661. 
Lemaire, P., Darras, S., Caillol, D., and Kodjabachian, L. 1998. A role for the vegetally expressed Xenopus gene Mix.1 in endoderm formation and in the restriction of mesoderm to the marginal zone. Development 125: 2371-2380.

Lengyel, J.A. and Iwaki, D.D. 2002. It takes guts: The Drosophila hindgut as a model system for organogenesis. Dev. Biol. 243: 1-19

Li, X., Wikramanayake, A.H., and Klein, W.H. 1999. Requirement of SpOtx in cell fate decisions in the sea urchin embryo and possible role as a mediator of $\beta$-catenin signaling. Dev. Biol. 212: 345-357.

Lin, R., Thompson, S., and Priess, J.R. 1995. pop-1 encodes an HMG box protein required for the specification of a mesoderm precursor in early C. elegans embryos. Cell 83: 599609.

Logan, C.Y., Miller, J.R., Ferkowicz, M.J., and McClay, D.R. 1999. Nuclear $\beta$-catenin is required to specify vegetal cell fates in the sea urchin embryo. Development 126: 345-357.

Lowe, L.A., Yamada, S., and Kuehn, M.R. 2001. Genetic dissection of nodal function in patterning the mouse embryo. Development 128: 1831-1843.

Lustig, K.D., Kroll, K.L., Sun, E.E., and Kirschner, M.W. 1996. Expression cloning of a Xenopus T-related gene (Xombi) involved in mesodermal patterning and blastopore lip formation. Development 122: 4001-4012.

Maduro, M.F., Meneghini, M.D., Bowerman, B., BroitmanMaduro, G., and Rothman, J.H. 2001. Restriction of mesendoderm to a single blastomere by the combined action of SKN- 1 and a GSK- $3 \beta$ homolog is mediated by MED- 1 and -2 in C. elegans. Mol. Cell 7: 475-485.

Maeda, M., Kubo, K., Nishi, T., and Futai, M. 1996. Roles of gastric GATA DNA-binding proteins. J. Exp. Biol. 199: 513520.

Mango, S.E., Lambie, E.J., and Kimble, J. 1994. The pha-4 gene is required to generate the pharyngeal primordium of Caenorhabditis elegans. Development 120: 3019-3031.

McClay, D.R., Peterson, R.E., Range, R.C., Winter-Vann, A.M., and Ferkowicz, M.J. 2000. A micromere induction signal is activated by $\beta$-catenin and acts through notch to initiate specification of secondary mesenchyme cells in the sea urchin embryo. Development 127: 5113-5122.

Mead, P.E., Brivanlou, I.H., Kelley, C.M., and Zon, L.I. 1996. BMP-4-responsive regulation of dorsal-ventral patterning by the homeobox protein Mix.1. Nature 382: 357-360.

Meneghini, M.D., Ishitani, T., Carter, J.C., Hisamoto, N., Ninomiya-Tsuji, J., Thorpe, C.J., Hamill, D.R., Matsumoto, K., and Bowerman, B. 1999. MAP kinase and Wnt pathways converge to downregulate an HMG-domain repressor in Caenorhabditis elegans. Nature 399: 793-797.

Meno, C., Gritsman, K., Ohishi, S., Ohfuji, Y., Heckscher, E., Mochida, K., Shimono, A., Kondoh, H., Talbot, W.S., Robertson, E.J., et al. 1999. Mouse Lefty2 and zebrafish Antivin are feedback inhibitors of Nodal signaling during vertebrate gastrulation. Mol. Cell 4: 287-298.

Mione, M., Shanmugalingam, S., Kimelman, D., and Griffin, K. 2001. Overlapping expression of zebrafish T-brain-1 and eomesodermin during forebrain development. Mech. Dev. 100: 93-97.

Molkentin, J.D. 2000. The zinc finger-containing transcription factors GATA-4, -5 , and -6. Ubiquitously expressed regulators of tissue-specific gene expression. J. Biol. Chem. 275: 38949-38952.

Morrisey, E.E., Tang, Z., Sigrist, K., Lu, M.M., Jiang, F., Ip, H.S., and Parmacek, M.S. 1998. GATA6 regulates HNF4 and is required for differentiation of visceral endoderm in the mouse embryo. Genes \& Dev. 12: 3579-3590.
Myat, M.M. and Andrew, D.J. 2000. Fork head prevents apoptosis and promotes cell shape change during formation of the Drosophila salivary glands. Development 127: 4217-4226.

Nishida, H. 1987. Cell lineage analysis in ascidian embryos by intracellular injection of a tracer enzyme. III. Up to the tissue restricted stage. Dev. Biol. 121: 526-541.

- 1992. Developmental potential for tissue differentiation of fully dissociated cells of the ascidian embryo. Roux's Arch. Dev. Biol. 201: 81-87.

- 1993. Localized regions egg cytoplasm that promote expression of endoderm-specific alkaline phosphatase in embryos of the ascidian Halocynthia roretzi. Development 118: $1-7$.

Nomura, M. and Li, E. 1998. Smad2 role in mesoderm formation, left-right patterning and craniofacial development. $\mathrm{Na}$ ture 393: 786-790.

Odenthal, J. and Nüsslein-Volhard, C. 1998. fork head domain genes in zebrafish. Dev. Genes Evol. 208: 245-258.

Orkin, S.H. and Zon, L.I. 1997. Genetics of erythropoiesis: Induced mutations in mice and zebrafish. Annu. Rev. Genet. 31: 33-60.

Osada, S.I. and Wright, C.V. 1999. Xenopus nodal-related signaling is essential for mesendodermal patterning during early embryogenesis. Development 126: 3229-3240.

Pearce, J.J. and Evans, M.J. 1999. Mml, a mouse Mix-like gene expressed in the primitive streak. Mech. Dev. 87: 189-192.

Peyrieras, N., Strahle, U., and Rosa, F. 1998. Conversion of zebrafish blastomeres to an endodermal fate by TGF- $\beta$-related signaling. Curr. Biol. 8: 783-786.

Pogoda, H.M., Solnica-Krezel, L., Driever, W., and Meyer, D. 2000. The zebrafish forkhead transcription factor FoxH1/ Fast1 is a modulator of nodal signaling required for organizer formation. Curr. Biol. 10: 1041-1049.

Randall, R.A., Germain, S., Inman, G.J., Bates, P.A., and Hill, C.S. 2002. Different Smad2 partners bind a common hydrophobic pocket in Smad2 via a defined proline-rich motif. $E M B O$ J. 21: 145-156.

Rehorn, K.P., Thelen, H., Michelson, A.M., and Reuter, R. 1996. A molecular aspect of hematopoiesis and endoderm development common to vertebrates and Drosophila. Development 122: 4023-4031.

Reiter, J.F., Alexander, J., Rodaway, A., Yelon, D., Patient, R., Holder, N., and Stainier, D.Y. 1999. Gata5 is required for the development of the heart and endoderm in zebrafish. Genes \& Dev. 13: 2983-2995.

Reiter, J.F., Kikuchi, Y., and Stainier, D.Y. 2001. Multiple roles for Gata5 in zebrafish endoderm formation. Development 128: $125-135$.

Reuter, R. 1994. The gene serpent has homeotic properties and specifies endoderm versus ectoderm within the Drosophila gut. Development 120: 1123-1135.

Reuter, R. and Leptin, M. 1994. Interacting functions of snail, twist, and huckebein during the early development of germ layers in Drosophila. Development 120: 1137-1150.

Ristoratore, F., Spagnuolo, A., Aniello, F., Branno, M., Fabbrini, F., and Di Lauro, R. 1999. Expression and functional analysis of Cititf1, an ascidian NK-2 class gene, suggest its role in endoderm development. Development 126: 5149-5159.

Robb, L., Hartley, L., Begley, C.G., Brodnicki, T.C., Copeland, N.G., Gilbert, D.J., Jenkins, N.A., and Elefanty, A.G. 2000 Cloning, expression analysis, and chromosomal localization of murine and human homologues of a Xenopus Mix gene. Dev. Dyn. 219: 497-504

Rocheleau, C.E., Yasuda, J., Shin, T.H., Lin, R., Sawa, H., Okano, H., Priess, J.R., Davis, R.J., and Mello, C.C. 1999. WRM-1 activates the LIT-1 protein kinase to transduce an- 
terior/posterior polarity signals in C. elegans. Cell 97: 717726.

Rodaway, A., Takeda, H., Koshida, S., Broadbent, J., Price, B., Smith, J.C., Patient, R., and Holder, N. 1999. Induction of the mesendoderm in the zebrafish germ ring by yolk cellderived TGF- $\beta$ family signals and discrimination of mesoderm and endoderm by FGF. Development 126: 3067-3078.

Rosa, F.M. 1989. Mix.1, a homeobox mRNA inducible by mesoderm inducers, is expressed mostly in the presumptive endodermal cells of Xenopus embryos. Cell 57: 965-974.

Russ, A.P., Wattler, S., Colledge, W.H., Aparicio, S.A., Carlton, M.B., Pearce, J.J., Barton, S.C., Surani, M.A., Ryan, K., Nehls, M.C., et al. 2000. Eomesodermin is required for mouse trophoblast development and mesoderm formation. Nature 404: 95-99.

Salomon, D.S., Bianco, C., and De Santis, M. 1999. Cripto: A novel epidermal growth factor (EGF)-related peptide in mammary gland development and neoplasia. BioEssays 21: 61-70.

Sasai, Y., Lu, B., Piccolo, S., and De Robertis, E.M. 1996. Endoderm induction by the organizer-secreted factors chordin and noggin in Xenopus animal caps. EMBO J. 15: 4547-4555.

Sasaki, H. and Hogan, B.L. 1993. Differential expression of multiple fork head related genes during gastrulation and axial pattern formation in the mouse embryo. Development 118: $47-59$

Satou, Y., Imai, K.S., and Satoh, N. 2001. Early embryonic expression of a LIM-homeobox gene Cs-lhx3 is downstream of $\beta$-catenin and responsible for the endoderm differentiation in Ciona savignyi embryos. Development 128: 3559-3570.

Schier, A.F., Neuhauss, S.C., Helde, K.A., Talbot, W.S., and Driever, W. 1997. The one-eyed pinhead gene functions in mesoderm and endoderm formation in zebrafish and interacts with no tail. Development 124: 327-342.

Sherwood, D.R. and McClay, D.R. 1999. LvNotch signaling mediates secondary mesenchyme specification in the sea urchin embryo. Development 126: 1703-1713.

- 2001. LvNotch signaling plays a dual role in regulating the position of the ectoderm-endoderm boundary in the sea urchin embryo. Development 128: 2221-2232.

Shin, T.H., Yasuda, J., Rocheleau, C.E., Lin, R., Soto, M., Bei, Y., Davis, R.J., and Mello, C.C. 1999. MOM-4, a MAP kinase kinase kinase-related protein, activates WRM-1/LIT-1 kinase to transduce anterior/posterior polarity signals in $C$. elegans. Mol. Cell 4: 275-280.

Shoichet, S.A., Malik, T.H., Rothman, J.H., and Shivdasani, R.A. 2000. Action of the Caenorhabditis elegans GATA factor END-1 in Xenopus suggests that similar mechanisms initiate endoderm development in ecdysozoa and vertebrates. Proc. Natl. Acad. Sci. 97: 4076-4081.

Sirotkin, H.I., Gates, M.A., Kelly, P.D., Schier, A.F., and Talbot, W.S. 2000. Fast 1 is required for the development of dorsal axial structures in zebrafish. Curr. Biol. 10: 1051-1054.

Stennard, F., Carnac, G., and Gurdon, J.B. 1996. The Xenopus T-box gene, Antipodean, encodes a vegetally localised maternal mRNA and can trigger mesoderm formation. Development 122: 4179-4188.

Sulston, J.E., Schierenberg, E., White, J.G., and Thomson, J.N. 1983. The embryonic cell lineage of the nematode Caenorhabditis elegans. Dev. Biol. 100: 64-119.

Sun, B.I., Bush, S.M., Collins-Racie, L.A., LaVallie, E.R., DiBlasio-Smith, E.A., Wolfman, N.M., McCoy, J.M., and Sive, H.L. 1999. Derriere: A TGF- $\beta$ family member required for posterior development in Xenopus. Development 126: 14671482.

Tada, M., Casey, E.S., Fairclough, L., and Smith, J.C. 1998. Bix1, a direct target of Xenopus T-box genes, causes formation of ventral mesoderm and endoderm. Development 125: 39974006.

Thisse, C. and Thisse, B. 1999. Antivin, a novel and divergent member of the TGF $\beta$ superfamily, negatively regulates mesoderm induction. Development 126: 229-240.

Thisse, B., Wright, C.V., and Thisse, C. 2000. Activin- and Nodal-related factors control antero-posterior patterning of the zebrafish embryo. Nature 403: 425-428.

Thorpe, C.J., Schlesinger, A., Carter, J.C., and Bowerman, B. 1997. Wnt signaling polarizes an early C. elegans blastomere to distinguish endoderm from mesoderm. Cell 90: 695-705.

Thorpe, C.J., Schlesinger, A., and Bowerman, B. 2000. Wnt signalling in Caenorhabditis elegans: Regulating repressors and polarizing the cytoskeleton. Trends. Cell. Biol. 10: 1017.

Tremblay, K.D., Hoodless, P.A., Bikoff, E.K., and Robertson, E.J 2000. Formation of the definitive endoderm in mouse is a Smad2-dependent process. Development 127: 3079-3090.

Vize, P.D. 1996. DNA sequences mediating the transcriptional response of the Mix.2 homeobox gene to mesoderm induction. Dev. Biol. 177: 226-231.

Waldrip, W.R., Bikoff, E.K., Hoodless, P.A., Wrana, J.L., and Robertson, E.J. 1998. Smad2 signaling in extraembryonic tissues determines anterior-posterior polarity of the early mouse embryo. Cell 92: 797-808.

Warga, R.M. and Nüsslein-Volhard, C. 1999. Origin and development of the zebrafish endoderm. Development 126: 827838.

Warga, R.M. and Stainier, D.Y.R. 2002. The guts of endoderm formation. In Pattern formation in zebrafish (ed. L. SolnicaKrezel), Springer-Verlag, New York, NY (in press).

Watanabe, M. and Whitman, M. 1999. FAST-1 is a key maternal effector of mesoderm inducers in the early Xenopus embryo. Development 126: 5621-5634.

Weber, H., Symes, C.E., Walmsley, M.E., Rodaway, A.R., and Patient, R.K. 2000. A role for GATA5 in Xenopus endoderm specification. Development 127: 4345-4360.

Weigel, D., Jurgens, G., Kuttner, F., Seiffert, E., and Jackle, H. 1989. The homeotic gene fork head encodes a nuclear protein and is expressed in the terminal regions of the Drosophila embryo. Cell 57: 645-658.

Weinstein, D.C., Ruiz i Altaba, A., Chen, W.S., Hoodless, P., Prezioso, V.R., Jessell, T.M., and Darnell, Jr., J.E. 1994. The winged-helix transcription factor HNF-3 $\beta$ is required for notochord development in the mouse embryo. Cell 78: 575588.

Weinstein, M., Yang, X., Li, C., Xu, X., Gotay, J., and Deng, C.X. 1998. Failure of egg cylinder elongation and mesoderm induction in mouse embryos lacking the tumor suppressor Smad2. Proc. Nat1. Acad. Sci. 95: 9378-9383.

Wells, J.M. and Melton, D.A. 1999. Vertebrate endoderm development. Annu. Rev. Cell. Dev. Biol. 15: 393-410.

Whitman, M. 2001. Nodal signaling in early vertebrate embryos. Themes and variations. Dev. Cell 1: 605-617.

Whittaker, J.R. 1990. Determination of alkaline phosphatase expression in endodermal cell lineages of an ascidian embryo. Biol. Bull. 178: 222-230.

Xanthos, J.B., Kofron, M., Wylie, C., and Heasman, J. 2001. Maternal VegT is the initiator of a molecular network specifying endoderm in Xenopus laevis. Development 128: 167180.

Yamamoto, M., Meno, C., Sakai, Y., Shiratori, H., Mochida, K., Ikawa, Y., Saijoh, Y., and Hamada, H. 2001. The transcription factor FoxH1 (FAST) mediates Nodal signaling during anterior-posterior patterning and node formation in the 
mouse. Genes \& Dev. 15: 1242-1256.

Yasuo, H. and Lemaire, P. 1999. A two-step model for the fate determination of presumptive endodermal blastomeres in Xenopus embryos. Curr. Biol. 9: 869-879.

Yeo, C. and Whitman, M. 2001. Nodal signals to Smads through Cripto-dependent and Cripto-independent mechanisms. Mol. Cell 7: 949-957.

Yuh, C.H., Bolouri, H., and Davidson, E.H. 1998. Genomic cisregulatory logic: Experimental and computational analysis of a sea urchin gene. Science 279: 1896-1902.

2001. Cis-regulatory logic in the endo16 gene: Switching from a specification to a differentiation mode of control. Development 128: 617-629.

Zhang, J. and King, M.L. 1996. Xenopus VegT RNA is localized to the vegetal cortex during oogenesis and encodes a novel T-box transcription factor involved in mesodermal patterning. Development 122: 4119-4129.

Zhang, J., Talbot, W.S., and Schier, A.F. 1998a. Positional cloning identifies zebrafish One-eyed pinhead as a permissive EGF-related ligand required during gastrulation. Cell 92: 241-251

Zhang, J., Houston, D.W., King, M.L., Payne, C., Wylie, C., and Heasman, J. 1998b. The role of maternal VegT in establishing the primary germ layers in Xenopus embryos. Cell 94: 515-524.

Zhong, W., Sladek, F.M., and Darnell, Jr., J.E. 1993. The expression pattern of a Drosophila homolog to the mouse transcription factor HNF-4 suggests a determinative role in gut formation. $E M B O$ J. 12: 537-544.

Zhu, J., Hill, R.J., Heid, P.J., Fukuyama, M., Sugimoto, A., Priess, J.R., and Rothman, J.H. 1997. end-1 encodes an apparent GATA factor that specifies the endoderm precursor in Caenorhabditis elegans embryos. Genes \& Dev. 11:28832896.

Zhu, J., Fukushige, T., McGhee, J.D., and Rothman, J.H. 1998. Reprogramming of early embryonic blastomeres into endodermal progenitors by a Caenorhabditis elegans GATA factor. Genes \& Dev. 12: 3809-3814. 


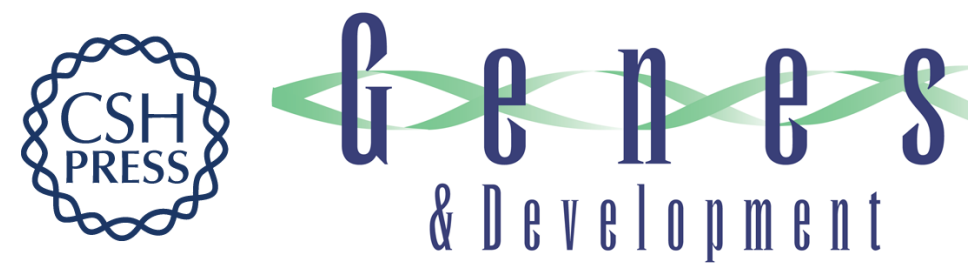

\title{
A glimpse into the molecular entrails of endoderm formation
}

\author{
Didier Y.R. Stainier
}

Genes Dev. 2002, 16:

Access the most recent version at doi:10.1101/gad.974902

References This article cites 143 articles, 78 of which can be accessed free at: http://genesdev.cshlp.org/content/16/8/893.full.html\#ref-list-1

\section{License}

Email Alerting Receive free email alerts when new articles cite this article - sign up in the box at the top right corner Service of the article or click here.

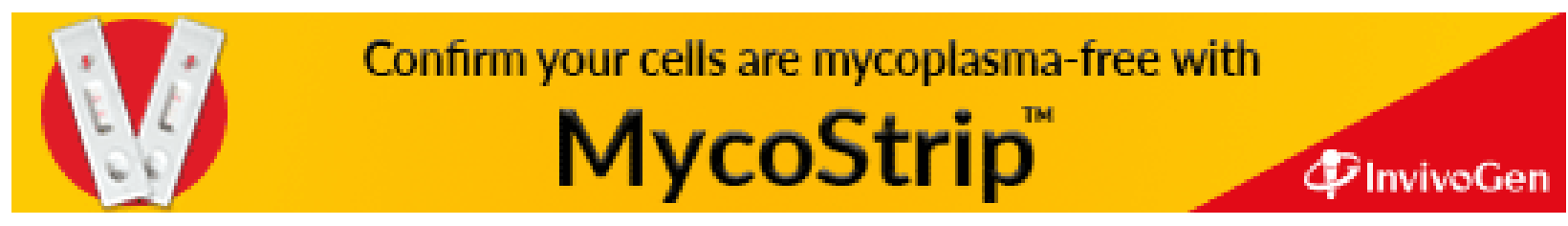

